\title{
Liquidity of a Stock Exchange, Between Investor Behavior and Scarcity of Securities: The Case Study of the West African Regional Stock Exchange
}

\author{
Pourakin Djarius Dieudonné Bama ${ }^{1, *}$, Balibié Serge Auguste Bayala ${ }^{2}$ \\ ${ }^{1}$ Department of Management, Ouaga II University, Faculty of Economics and Management Science, Ouagadougou-Burkina Faso, \\ Ouagadougou, Burkina Faso \\ ${ }^{2}$ Department of Management, Ouaga II University, Faculty of Economics and Management Science, Ouagadougou-Burkina Faso, Centre \\ Africain d'Etudes Supérieures en Gestion (CESAG), Dakar, Sénégal
}

Email address:

djarius.aud $a$ gmail.com (P. D. D. Bama), sbayala $a$ gmail.com (B. S. A. Bayala)

${ }^{*}$ Corresponding author

\section{To cite this article:}

Pourakin Djarius Dieudonné Bama, Balibié Serge Auguste Bayala. Liquidity of a Stock Exchange, Between Investor Behavior and Scarcity of Securities: The Case Study of the West African Regional Stock Exchange. International Journal of Business and Economics Research. Vol. 8, No. 6, 2019, pp. 389-398. doi: 10.11648/j.ijber.20190806.19

Received: September 27, 2019; Accepted: November 4, 2019; Published: November 21, 2019

\begin{abstract}
Liquidity may be evident at first glance, as it is widely debated in the literature, but regarding the question on the threshold at which a stock market is liquid, the answers are far from being evident and unanimous. This paper studies the determinants of liquidity in the West African Regional Stock Exchange through the level of float and investors behavior based on a conceptual model. The model takes into account the specificities of a market governed by players' orders and behaviors. We analysed the scarcity of stocks and the behaviors of players based on a case study and simulation methodology. We found that investors are passive in the market, which results in under-liquidity. It can be deduced that the market is savings driven. In addition, the average time that a stock market order finds a counterpart is three to seven days. This situation is due to the scarcity of securities and / or the inability of investors to intervene in the market in a timely manner. As a result, new entrants to the market will have difficulty in offering securities, due to a lack of sufficient liquidity. In conclusion, the market liquidity depends mainly on a minimum of auctioned securities rather than investor's participation.
\end{abstract}

Keywords: Liquidity, Behavior, Depth of the Market, Scarcity of Securities, Regional Stock Exchange

\section{Introduction}

Market liquidity may appear at first glance, as an issue widely addressed in the literature, but on the issue of the level of the stock market liquidity, the answers are far from being clear and unanimous. Let's imagine that following a company public bid where an investor has taken significant shares, they may eventually want to leave the capital of the company for various reasons. The solution available to them will be to sell their shares on the market. The speed of the possibility of sale depends on the liquidity of the market. This means that one of the essential missions of a stock exchange is its liquidity [1]. This is why the liquidity of the stock markets has now become an issue involving both the market players and the academia [2]. Despite its regional nature and the fat that it has existed for two (2) decades, the Regional Stock Exchange (BRVM), is still struggling to register many big companies and to reach the level of the developed stock exchanges. It now has 44 listed companies compared with 36 when it was created in 1998. This means it takes about three (3) years on average for a new company to enter the market. Also, an investor needs to ask for at least two (02) or more shares to hope for a share [3]. This is due to the lack of securities in the market. One of the challenges it faces is surely its liquidity and its narrowness, due to the weak listing of popular companies. Over the last decade synonymous with constituting a precondition of efficiency, if it is true that efforts have been made by the stock market authorities (change of trading system, creation of a new departments for small caps, etc.) but, this does not 
necessarily attract investments [4]. An investor is all attracted, if the market offers him at every moment the opportunity to buy securities and resell them without waiting for a long time.

In the literature the influence of market microstructure has been put forward to explain the problem of liquidity [5-7]. The approach is essentially focused on the securities supply and demand according to the investor rationality principle. If it is true that investors are rational, that is to say able to make complex analyses in order to make a final decision, they are also limited to constraints that very often lead them to make shortcuts based on their intuitions and their emotions. These human constraints or imperfections very often play a determining role in the behavior of investors, leading to the introduction of the behavioral dimension, which is more realistic in economic analysis $[8,9]$. This article is totally in keeping with this market dynamics considering that there is a close link between the liquidity of the Regional Stock Exchange, the behavior of investors and the scarcity of securities. The rest of this paper is organized as follows: Section 2 presents the literature review on the main traditional approaches to liquidity, the limitations of empirical studies as well as the positioning of this paper. Section 3 deals with the methodology. This part presents a descriptive model of analysis, the game of players and research proposals. The main results of this methodology are presented in section 4 and discussed in section 5 . The last paragraph is a conclusion.

\section{Literature Review}

Liquidity has a polysemic dimension: volume, time, resilience, range $[5,6]$. It expresses the possibility of exchanging a security quickly without a significant price gap. Under these conditions, a security is all the more liquid if it is easily exchanged for money. Thus, liquidity is compared with the ease and speed at which a security can be traded on the market [6]. Consequently, a market is liquid if investors can quickly buy and sell a large number of securities without a significant effect on prices [10].

\subsection{Traditional Approaches to Liquidity}

Since Keynes emphasized for the first time in the 1930s the concept of liquidity to explain the demand for money, the concept has taken on a controversial dimension in literature. According to Keynes, the liquidity of an investment property is the speed with which the wealth that is incorporated into it can be recovered as quickly as possible without making a loss. Keynes's idea is to say that money is required for itself to meet transaction needs. This means that an investor's preference for liquidity appears as a choice between collecting financial income and collecting financial capital gains from his investments. Research made before Keynes has extended liquidity to various economic sectors such as financial markets. From this standpoint, the liquidity of a market reflects a market on which an investor can make large stock market transactions without causing significant price variation of securities. Research on the issue of market liquidity is vast and very diverse. However, initial study has raised the issue from the organization and operating system of the markets as well as from the volume of trade on the market [10-13]. Traditionally, liquidity has been studied using four (4) traditional indicators of width, immediacy, depth and resilience [5]. The second study examined the issue of liquidity taking into account the extent of the market. Market capitalization, trading volume, liquidity ratio and turnover ratio are the main indicators used [14].

The literature clearly shows the liquidity interest of a stock market, but the concept of liquidity itself has several concepts, which are neither simple to define nor easy to measure [15]. Since Keynes' studies, the concept of liquidity has been trendy but, the concept has terminological and statistical difficulties [16]. Most traders can tell whether a market is liquid or not but can rarely identify accurately all the factors that contribute to a market's liquidity [15]. This idea led to a comparison of liquidity and pornography, in the sense that it is difficult to define, but easy to recognize when seen [17]. Some empirical studies on liquidity point out that it partly goes hand in hand with the way in which stock exchange transactions are organized or regulated [18]. Thus liquidity has a socio-political nature [19]. This author argues that liquidity is not a natural fact. This means that it cannot happen through the traditional mechanism derived from the neoclassical theory of market operating, whereby supply and demand for securities must converge naturally towards a balance.

The balance in the stock exchanges, for example, is not a balance that results from anonymous forces because the supply and demand of securities are not, [20]. According to the latter, the balance of trade is a balance of decision. This means that human behaviors play a role in the production of liquidity. Indeed, the exchange in the stock market framework is the result of crossed interactions or of feeling between several players interfering. Liquidity is therefore the consequence. Exchange and liquidity are from this point of view, closely related concepts. Hence liquidity results from a sovereign collective choice that society may or may not make [19]. One can therefore wonder why agents exchange them. The reasons may be due to a need for liquidity (money) or an adjustment of the return / risk ratio [21]. There are two types of liquidity depending on the diversity of stock markets and their modes of operation. This is natural liquidity and artificial liquidity.

\subsubsection{Natural Liquidity}

The natural liquidity is the result of the meeting of a large volume of exchanges resulting from the will of the various participants. The literature compares those offering natural liquidity to or seeking it from investors wishing to exchange securities on the market without interference (liquidity contract or market making contract). Natural liquidity is found by the spontaneous compensation of buy and sell orders issued by investors. Offsetting results in the search for a balance price to offset the maximum of securities between 
buyers and sellers. Investors have the option of either placing buy or sell orders and offering liquidity, or of being done immediately against offers made by other investors and seeking liquidity. This choice results in the use of different orders [22]. The investor is a liquidity provider, if they submit a limit order. This technique consists of giving a maximum (minimum) price for which he is willing to buy (sell) the security. On the other hand, if he is a liquidity seeker, they submit an order at any price. In these circumstances, the investor's strategy is no longer limited to the choice of the quantity they wish to exchange, but also to the choice of the price at which he wishes to exchange. Thus, liquidity is considered to be offered by investors who submit limit orders [23]. However, market liquidity is also directly related to the floating level [14]. The higher the float is, the deeper the market is.

\subsubsection{Artificial Liquidity}

If natural liquidity simply results from the will expressed by investors, the production of artificial liquidity is based on market making contract concluded between issuers and intermediaries. This contract commits intermediaries to buy or sell securities on the market at a price set in advance and for a given range. In fact, since natural liquidity is insufficient (quantity of securities for sale or purchase) or does not allow the exchange of a large volume of given securities, the market authorities are required to request additional liquidity, thanks to the intervention of financial intermediaries who offer (buy) a certain number of securities on the market. The idea is to revive the liquidity of securities that are not often processed or traded on the market [24]. The market, by investigating 25 securities subjects to a liquidity contract on the Paris Stock Exchange, indicates a significant improvement in volumes traded but seems to question the real effects of contracts on the liquidity of securities. These doubts are confirmed by some authors such as [25]. Indeed, these authors are studying the use of market making contracts to improve the volumes of securities traded on Alternext. Out of 25 companies that have entered into liquidity contracts, results indicate that, 9 companies have experienced a significant improvement in the trading volume of their securities, 4 have registered a decrease and 12 have not noticed a significant difference after the conclusion of the contract. This suggests that the use of liquidity contracts does not really have a positive effect on the volume of exchanged.

\subsection{The Limitations of Previous Studies}

Several variables have admittedly been highlighted in the literature to explain the liquidity of a market, but each one has its weaknesses because of the methodology and statistics used to assess liquidity [7]. We can learn from this that the work done on liquidity is highly instructive, but they face two major limitations. First, they do not indicate a threshold from which a market can be considered liquid. Secondly, the liquidity of the market is studied very often, by referring to the individual liquidity of a security, whereas each security has its own characteristics which determine its liquidity [6, 12]. The last mentioned, thus assumes that the individual liquidity of a security is different from that of the market. In light of this study, the market liquidity occurs when there is the possibility of making large exchanges (volume) in a shorter time (turnaround time) and without significant price gap (price of execution). Several theoretical explanations have been developed to explain it, among which, two measures seem to rally more votes [26]. This is the range and the lambda proposed respectively by [5] and [27]. By the sampling, the idea was to show that when it narrows, that is to say, the difference between the selling price and the purchase price is narrow, the market is liquid because the expression of sellers and buyers is similar. This idea is debatable.

Assuming that the difference between seller's and buyer's price is nil or at least marginal. In this case, in the sense of the range, an exchange should necessarily take place, because there is a near balance between supply and demand in terms of price. However, we can have a significant imbalance in terms of the securities quantities traded. All things being equal, assuming the growth of the offer of an investor offering for sale $10 i$ securities for $X$ francs and that of the request of another wishing $50 i$ for $X$ francs in these conditions, 10 securities are immediately exchanged but, an important part of the request is unsatisfied and will remain in the order book hoping to find a counterpart. The market is liquid in the sense of volume, when the quantities traded on the market are large. However, a large volume of securities traded can run in a market thanks to the dynamism of the shares of a small number of companies. In this case, these securities may be considered liquid without the market being global. Another important aspect of its dimension is the concept "time". Imagine that an investor can exchange or perform their operation in one day, another in three (03) days and a last one in one week. Without doubt, the perception of the liquidity of the market is not the same for each of them. As a justification, a survey was conducted on the immediacy of the exchange based on 150 responses received through a questionnaire to 825 participants [28]. It indicates that $71 \%$ consider an exchange to be immediate or instant if it can be done in less than 10 minutes, $14.7 \%$ in 1 hour, and $6 \%$ in 1 day. The diversity of opinions reflects the difficulty of accurately defining the maximum time from which a stock market order is executed instantly.

\subsection{The Positioning of the Search}

The activity of the market is the result of a collective action, from the game of all actors' individual behaviors; that are the listed companies, the stock market authorities and the investors. This is to say that the stock market is a play area for players who are both strategists and opportunists. Indeed, investors act on the market depending on the circumstances or situations in order to use them in their best interests. Market authorities are responsible not only for regulation, but also for market 
surveillance and the control of the operations that take place there. Their roles are mainly to define a wellstructured exchange framework to ensure the smooth running of the market. They ensure the quality and transparency of the information. The aim is to strengthen investor confidence by creating a space that is adapted to their needs and at the same time to ensure there are honest transactions [29]. Therefore, a challenge is needed. That of finding a balance to meet the investor's needs, the transparency of operations, the attraction of issuers and investors. Even if they are well regulated, companies agree to go on the market when they have the need to. While historically the raising of capital has been put forward, in favor of the creation of stock markets, companies sometimes go on the stock market for the needs of reputation or image $[25,30,31]$. The diversity of the player's motivations (stock market authorities, investors, issuers) suggests that the liquidity of the market may be dependent on their different behaviors. This research is therefore different from previous work on liquidity to study the liquidity of the market in the context of a model that takes into account the specificities of a market governed by the orders and behaviors of all its stakeholders. We believe that taking into account the scarcity of securities and the behavior of the players is worth of providing a more faithful explanation of the subliquidity of the market in general and specifically that of the Regional Stock Exchange.

\section{Methodological Approach}

This research is an applied research as it emphasizes on the explanation of a phenomenon rather than the theorization of the phenomenon itself. From this point of view, the research methodology is deductive and inductive. Indeed, it is designed on the basis of an explanatory model of the deductive method on the one hand, and uses the inductive method of data collection on the other hand within the meaning of $[32,33]$. As there has been no empirical studies conducted on the link between market liquidity, investor behavior and the scarcity of securities, research proposals are formulated. The methodology is therefore inspired by a case study and simulation of the behavior of the players on the market. This case study illustrates the process of liquidity production as seen in practice on the Regional Stock Exchange.

\subsection{The Model}

This research focusses on a phenomenon whereby the angle of study is worth defining [33]. Given this positioning, it is necessary to set a framework of analysis so as to make intelligible the phenomenon to be studied. As a result, we will rely on a conceptual diagram (figure 1) that highlights the structure of the players, the supply and demand of securities and the process of producing liquidity on the

\section{Regional Stock Exchange.}

It represents an overall structure as well as the major interactions between the market and the main actors required for the exchanges, as shown in the figure below. The figure shows a combination of structural approaches that result, on the one hand, from lessons learned from the literature and, on the other hand, from our view on the organization of trade in a governed-orders market, like the Regional Stock Exchange. By agreeing that the production of market liquidity is the result of a collective game of all market participants, we can design a model that structures all the main market players as well as the major interactions between the market participants, them and the market - the game they play and the observations.

The figure highlights first how players are structured, second, the supply and demand of securities, as well as the process of producing liquidity. It illustrates the problem of market liquidity in general and that of the Regional Stock Exchange in a specific way - by describing the interactions of the main market players represented by oval nodes. Rectangles reflect the behavior of market players. Market authorities are considered as neutral players in trade or at least have a marginal role in producing liquidity because they are not active players. In the end, we can consider two major players, companies and investors. From this viewpoint, the production of liquidity depends on a super player. These are companies because of the level of their floating in the market. This suggests that the global (floating) supply of securities depends on the number of firms that are floated on the stock market - that is, the fewer companies go public, the less floating securities are sold. This means that the float remains stable regardless of the flow of purchase or sale of investors. However, the flow of purchase / sale of the latter is a function of their behavior. Moreover, the model assumes that after its IPO, the company becomes neutral. This assumes that it no longer participates in the market making unless it is an institutional investor (legal person). In this case, their behavior is interpreted as that of an individual investor (natural person).

The model considers that investors have the opportunity to lock up the securities (equity) over a long period of time or to speculate in the short term. In this case, it can be deduced that investors' preferences relate to dividends when the securities are locked-in and, on stock appreciation when they speculate. This assumes that the production of liquidity is not the same in all cases. When investors' motives are focused on dividends, they sell less securities. As a result, securities are scarce on the market. On the other hand, if they are in a speculative logic, we can expect a massive proposal of securities on the market and in turn the liquidity of the market. In this case, the liquidity is reproduced by the investors, even without changing the structure of the overall offer of securities initially issued by the companies. From this point of view, the quantity of securities on the market simply depends on the investors' behavior. 


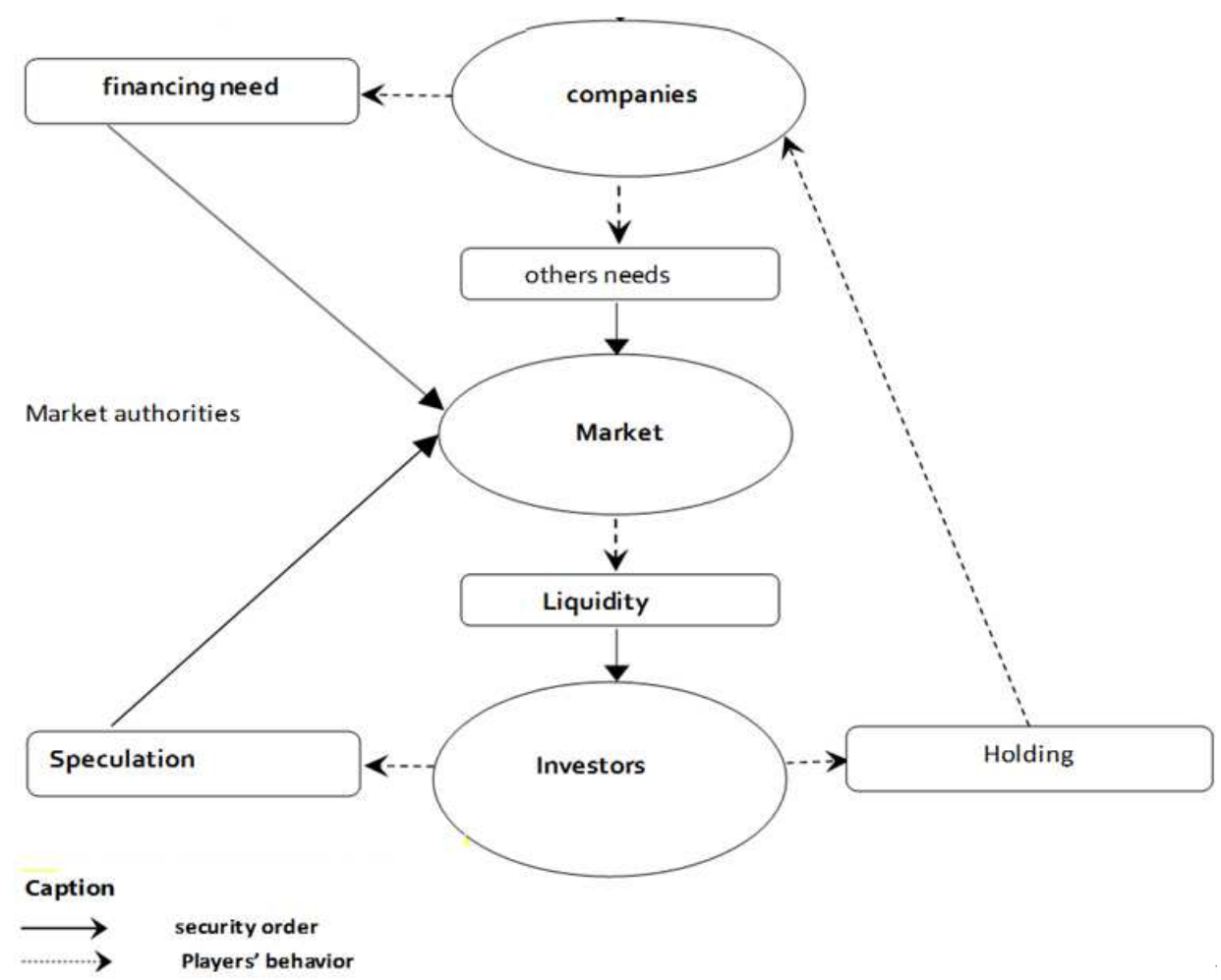

Source: Bama, P. D. D \& Bayala, B. S. A

Figure 1. Model illustrating market exchanges in West African Stock Exchange share compartment.

\subsection{The Game}

The model makes it possible to consider the market as a set of players where the investors are the consumers of securities and the listed companies the producers. The exchanges that result from their interactions lead us to think of a free and dynamic game, therefore non-cooperative insofar as each pursues its own interests, according to the principle of economic rationality. Like any game, the rules of the game here are stopped or even defined (regulated) by the market authorities. The idea of this regulation is to arrive at a balance of negotiations between the actors. The questions are therefore, how to regulate the balance in a market where the demand and supply of securities are balanced? Is this balance permanent at every trading session? This questioning raises the complexity of the rules to be defined in order to guarantee or stimulate a large volume of exchanges and even transactions.

To face this issue, the solution is to compel (market making contracts) certain intermediaries to buy (or sell) securities when the market is in a situation of imbalance to converge towards a satisfactory balance. This case is similar to a cooperative game. Thus, the stock market liquidity is the result of the collective behavior of the players. It comes from a cooperative game (artificial liquidity) and a noncooperative game (natural liquidity).

In considering an investor who wants to buy / sell, one can imagine that the fate of each investor (player) depends not only on the decisions (strategies) it takes but also decisions made by other players. Let's take the case of speculation only. Speculating on the stock exchange voluntarily returns to bet on the upward fluctuation of prices for the seller and downward for the buyer. When an investor decides to speculate, three things can happen, everything else being equal. Either they win or they lose or neither, under the hypothesis of nullity of the transaction costs. A priori, the will of the investor is to win on the principle of rationality. The other two alternatives that can occur are only the consequence of their decision. The theory of expected utility postulates in such a situation that individuals seek to win and avoid losing. From the outset, that is, before making the decision, the investor will be restrained from making a decision when it is uncertain. Ased on this, one can therefore formulate research proposals.

\subsection{Research Proposals and Modeling}

We therefore propose to know, on the one hand, whether investors on the Regional Stock Exchange are in a logic of immobilization of securities and, on the other hand, whether they can buy or sell immediately or instantly under the use liquidity contracts. However, there is no threshold from which a stock market transaction or execution of a stock market order is assumed instantaneous or immediate. We will therefore consider that it is immediate if it takes place on a trading day, otherwise it is assumed not immediate under the abstraction of securities prices. When an investor places a purchase order that is not instantly executed on the market, it is assumed that there is no immediate counterparty (sell order). This lack of consideration indicates that investors do not agree to sell, which means that the market is not deep (scarcity of securities), therefore under-liquidity. 
By submitting to the management companies and intermediation of the Regional Stock Exchange a series of items rated $\mathrm{k},(\mathrm{k}=1,2, \ldots, \mathrm{p})$ on the best-before date of securities, the waiting time to buy / sell and the immediacy in the execution of stock exchange orders, it is possible to quantitatively evaluate the score of each item. Assuming we observe the values taken by $\mathrm{p}$ items in $\mathrm{n}$ subjects. The data obtained can be represented in an individual - items array with $\mathrm{n}$ rows and $\mathrm{p}$ columns, in which the individuals are designated by $i,(i=1,2, \ldots n)$. The value observed on the item $\mathrm{k}$ for the individual $\mathrm{i}$ is denoted $\mathrm{x}_{-}(\mathrm{i}, \mathrm{k})$, denoting the weight of each item per individual. For each item, we perform the sum of the weights assigned. The score noted S, is calculated by dividing this sum of the weights by the maximum of the scores. Otherwise, the score is obtained by the following relation:

$$
S_{k}=\sum_{i=1}^{n} x_{i, k} / \sum_{k=1}^{p}\left(\sum_{i=1}^{n} x_{i, k}\right)
$$

With:

S_k, the score of item $\mathrm{k}$,

$\mathrm{x} \_(\mathrm{i}, \mathrm{k})$, the weight assigned by individual $\mathrm{i}$ to item $\mathrm{k}$.

\subsection{Data}

Two types of data are used. This is secondary data on the float of 40 listed companies and primary data from a field survey of Management and Intermediation Societies (SGI) where a questionnaire is administered. The survey was conducted in August 2017. At this date, the Regional Stock Exchange has 43 listed companies and 22 active management and intermediation companies. The choice of the latter is justified for several reasons. First, IMSs have a monopoly on the trading of listed securities, that is, they are the only ability to trade securities on the Regional Exchange on behalf of investors. Secondly, investors often entrust them with securities management (delegated management). For all these reasons, we believe that they are pivotal players in understanding investor behavior and the mechanism for generating liquidity from the Regional Stock Exchange.

We fell into line with the latest data available on the float. They relate to those of the 2015 period. During this period, while the float of some companies remained stable, the float of others experienced an upward (capital increase) or downward (capital reduction) restructuring or a capital splitting of which some data are not available or discounted. Given this difficulty, we have eliminated these companies to retain only those whose data have been updated. These data have been collected from 34 companies. With respect to the survey data, we received responses from 11 participants out of the total 22 to whom the questionnaire is administered. This limited amount of data does not allow for further statistical analysis, but offers the possibility of performing descriptive analyses.

\section{Results and Discussions}

The data gathered and made available to us for the survey have been refined and made it possible to do some sorting. This has led to results that we think are important in terms of analysis. These results relate to the depth of the market in terms of the quantity of securities, the assets, the time it takes for a stock market to find a counterparty and the immediacy in the execution of orders.

\subsection{The Depth of the Market}

One of the important dimensions of a market's liquidity is its depth, i.e. the float or quantity of securities made public that can be traded on the market at any given moment. The graph below shows the depth of the Regional Stock Exchange by showing the trend of the securities issued by the issuers and those held in the account of the management and intermediation companies in the account of the investors.

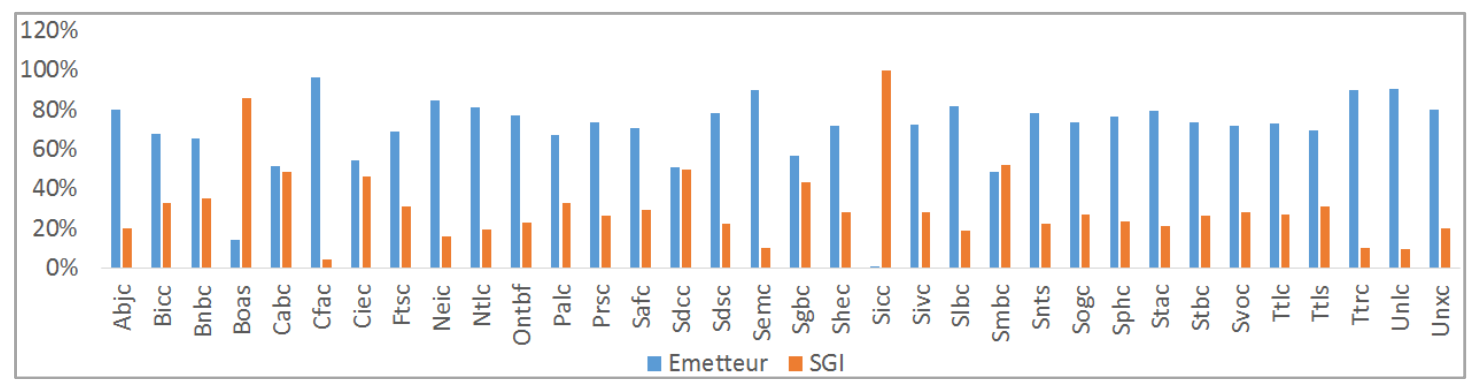

Source: Source: Bama, P. D. D \& Bayala, B. S. A

Figure 2. Trend of securities held by issuers and investors.

The chart analysis shows that not all of the securities of any company are available on the market. Much of the securities are in the hands of shareholders. These held or locked-in securities account for globally nearly $75 \%$ of all that are issued on the market. Otherwise, only $25 \%$ of the securities of companies listed by investors, via the market, are accessible.

\subsection{Duration of Securities by Investors}

The securities in the account of the management and intermediation companies are managed by them on behalf of the investors. Tables 1 and 2 show the average duration of stocks and bonds held by investors. 
Table 1. The average duration of stocks held by investors.

\begin{tabular}{lllll}
\hline \multirow{2}{*}{ Items } & Natural persons & & Legal persons & \\
\cline { 2 - 5 } & $\boldsymbol{S}_{\boldsymbol{k}}$ & $\boldsymbol{S}_{\boldsymbol{k}} \boldsymbol{e n} \%$ & $\boldsymbol{S}_{\boldsymbol{k}}$ & $\boldsymbol{S}_{\boldsymbol{k}}$ en $\%$ \\
\hline less than one week & 0 & $00.00 \%$ & 0 & $00.00 \%$ \\
from one to 2 weeks & 0 & $00.00 \%$ & 0 & $00.00 \%$ \\
from 2 weeks to a month & 0 & $00.00 \%$ & 0 & $00.00 \%$ \\
from a month to 3 months & 1 & $09.09 \%$ & 0 & $00.00 \%$ \\
From 3 to 6 months & 2 & $18.18 \%$ & 1 & $09.09 \%$ \\
from 6 months to a year & 1 & $09.09 \%$ & 1 & $09.09 \%$ \\
Over a year & 7 & $63.64 \%$ & 9 & $81.81 \%$ \\
Observations & 11 & $100.00 \%$ & 11 & $100.00 \%$ \\
\hline
\end{tabular}

Source: Source: Bama, P. D. D \& Bayala, B. S. A

Table 2. The average duration of bonds held by investors.

\begin{tabular}{|c|c|c|c|c|}
\hline \multirow[t]{2}{*}{ Items } & \multicolumn{2}{|c|}{ Natural persons } & \multicolumn{2}{|c|}{ Legal persons } \\
\hline & $S_{k}$ & $\mathbf{S}_{\mathrm{k}}$ en $\%$ & $S_{k}$ & $\mathbf{S}_{\mathrm{k}}$ en $\%$ \\
\hline less than one week & 0 & $0,00 \%$ & 0 & $0,00 \%$ \\
\hline from one to 2 weeks & 0 & $0,00 \%$ & 0 & $0,00 \%$ \\
\hline from 2 weeks to a month & 0 & $0,00 \%$ & 0 & $0,00 \%$ \\
\hline from a month to 3 months & 0 & $0,00 \%$ & 0 & $0,00 \%$ \\
\hline From 3 to 6 months & 0 & $0,00 \%$ & 0 & $0,00 \%$ \\
\hline from 6 months to a year & 1 & $9,09 \%$ & 2 & $18,18 \%$ \\
\hline Observations & 11 & $100 \%$ & 11 & $100,00 \%$ \\
\hline
\end{tabular}

Source: Source: Bama, P. D. D \& Bayala, B. S. A

The analysis in Tables 1 and 2 indicates that most investors hold their securities portfolios over a year before liquidating them, both for individual investors and institutional investors. Nine (9) out of eleven (11) participants in the survey indicate that many institutional investors hold stocks for a long time - while the trend appears to be reversing in bond retention.

\subsection{Waiting Time to Buy/Sell}

Tables 3 and 4 show the waiting time for investors to buy or sell stocks and bonds on the Regional Stock Exchange.

Table 3. Waiting time for investors to sell/buy an equity.

\begin{tabular}{|c|c|c|c|c|}
\hline \multirow{2}{*}{ Items } & \multicolumn{2}{|c|}{ Purchase } & \multicolumn{2}{|c|}{ Sales } \\
\hline & $S_{k}$ & $S_{k}$ en $\%$ & $S_{k}$ & $S_{k}$ en $\%$ \\
\hline Less than one hour & 2 & $18 \%$ & 2 & $18 \%$ \\
\hline One hour to three hours & 0 & $0 \%$ & 0 & $0 \%$ \\
\hline Three hours to a day & 3 & $27 \%$ & 2 & $18 \%$ \\
\hline A day to three days & 2 & $18 \%$ & 1 & $9 \%$ \\
\hline Three to seven days & 4 & $36 \%$ & 5 & $45 \%$ \\
\hline Seven to thirty days & 0 & $0 \%$ & 1 & $9 \%$ \\
\hline Thirty to sixty days & 0 & $0 \%$ & 0 & $0 \%$ \\
\hline Sixty to ninety days & 0 & $0 \%$ & 0 & $0 \%$ \\
\hline Observations & 11 & $100 \%$ & 11 & $110 \%$ \\
\hline
\end{tabular}

Source: Source: Bama, P. D. D \& Bayala, B. S. A

Table 4. Waiting time for investors to sell/ buy a bond.

\begin{tabular}{|c|c|c|c|c|}
\hline \multirow{2}{*}{ Items } & \multicolumn{2}{|c|}{ Purchase } & \multicolumn{2}{|c|}{ Sales } \\
\hline & $S_{k}$ & $\boldsymbol{S}_{\boldsymbol{k}}$ en $\%$ & $S_{k}$ & $S_{k}$ en $\%$ \\
\hline Less than one hour & 0 & $0,00 \%$ & 0 & $0,00 \%$ \\
\hline One hour to three hours & 0 & $0,00 \%$ & 0 & $0,00 \%$ \\
\hline three hours to a day & 0 & $0,00 \%$ & 0 & $0,00 \%$ \\
\hline A day to three days & 2 & $18,18 \%$ & 1 & $9,09 \%$ \\
\hline Three to seven days & 0 & $0,00 \%$ & 0 & $0,00 \%$ \\
\hline Seven to thirty days & 7 & $63,64 \%$ & 8 & $72,73 \%$ \\
\hline thirty to sixty days & 1 & $9,09 \%$ & 1 & $9,09 \%$ \\
\hline Sixty to ninety days & 1 & $9,09 \%$ & 1 & $9,09 \%$ \\
\hline Observations & 11 & $100 \%$ & 11 & $100 \%$ \\
\hline
\end{tabular}

Source: Source: Bama, P. D. D \& Bayala, B. S. A 
On average four investors out of 11 spend between three and seven days to buy/sell a share on the Regional Stock Exchange. In the case of bonds, they take on average more than seven days, or even more than one or two months. We deduce that it is difficult to achieve an immediate transaction due to the lack of counterparty.

\subsection{Immediacy in the Execution of Stock Market Orders}

It seems important to keep in mind that immediacy reflects the market's ability to instantly satisfy investor concerns in terms of buying or selling securities. In addition to the previous results, Tables 5 and 6 indicate respectively the ease or frequency or the immediacy to which investors acquire shares and bonds on the Regional Stock Exchange.

Table 5. Shares frequency of acquisition.

\begin{tabular}{lllll}
\hline \multirow{2}{*}{ Items } & \multicolumn{3}{c}{ Purchase } & \multicolumn{3}{c}{ Sales } \\
\cline { 2 - 5 } & $\mathbf{S}_{\mathbf{k}}$ & $\mathbf{S}_{\mathbf{k}}$ en $\%$ & $\mathbf{S}_{\mathbf{k}}$ & $\mathbf{S}_{\mathbf{k}}$ en $\%$ \\
\hline Very rarely & 0 & $00,00 \%$ & 0 & $00,00 \%$ \\
Rarely & 1 & $09,09 \%$ & 1 & $09,09 \%$ \\
Not at all & 1 & $09,09 \%$ & 2 & $18,18 \%$ \\
Often & 8 & $72,73 \%$ & 7 & $63,64 \%$ \\
Very often & 1 & $09,09 \%$ & 1 & $09,09 \%$ \\
Observations & 11 & $100,00 \%$ & 11 & $100,00 \%$ \\
\hline
\end{tabular}

Source: Source: Bama, P. D. D \& Bayala, B. S. A

Table 6. Bonds frequency of acquisition.

\begin{tabular}{lllll}
\hline \multirow{2}{*}{ Items } & \multicolumn{3}{c}{ Purchase } & \multicolumn{3}{c}{ Sale } \\
\cline { 2 - 5 } & $\boldsymbol{S}_{\boldsymbol{k}}$ & $\boldsymbol{S}_{\boldsymbol{k}}$ en $\%$ & $\boldsymbol{S}_{\boldsymbol{k}}$ & $\boldsymbol{S}_{\boldsymbol{k}}$ en $\%$ \\
\hline Very rarely & 2 & $18,18 \%$ & 2 & $18,18 \%$ \\
Rarely & 7 & $63,64 \%$ & 7 & $63,64 \%$ \\
Not at all & 0 & $00,00 \%$ & 0 & $00,00 \%$ \\
Often & 2 & $18,18 \%$ & 2 & $18,18 \%$ \\
Very often & 0 & $00,00 \%$ & 0 & $00,00 \%$ \\
Observations & 11 & $100,00 \%$ & 11 & $100,00 \%$ \\
\hline
\end{tabular}

Source: Source: Bama, P. D. D \& Bayala, B. S. A

The observation of investor acquisition frequencies shows that equities are more accessible than bonds. Eight (8) investors out of eleven (11) frequently buy shares compared to only two (2) for bonds.

\section{Discussions}

The results mentioned above reveal the liquidity of the Regional Stock Exchange through the behavior of investors in the market.

\subsection{The Impact of Market Making Contacts on Liquidity}

It should be remembered that liquidity contracts are intended to create, improve or bring liquidity to securities on the market. From this point of view, what is the real effect of these contracts in the context of exchanges for an investor to wait between 3 to 7 days to find a counterparty on the Regional Stock Exchange? By answering to this question, it is important to note that only three (3) out of eleven (11) management and intermediation companies have liquidity contracts. Only two (2) of the three (3) who have it, say they "rarely" implement that contract. This seems to confirm that liquidity contracts do not have a significant effect on trade, and therefore on the overall liquidity of the market. One could deduce that the creation of a global liquidity of the Regional Stock Exchange goes beyond the framework of the liquidity contracts. Other factors might explain it better. Others factors like, the narrowness of the level of the floating and the behavior of the investors.

\subsection{The Narrowness of the Floating, Investor Behavior}

The results reveal that the floating in addition to being narrow, is essentially kept by investors. It represents only $25 \%$ of the shares issued by companies listed on the Regional Stock Exchange where individual investors are less represented than institutional investors. Institutional investors usually have different motivations (control) from the former (speculation). The exercise of control involves holding the shares for a long time [34]. This behavior is likely to reduce the depth of the market. Thus, the possibility of buying or selling shares instantly or immediately is almost impossible because of the low liquidity of the market than such induced behavior.

Like the results of the survey conducted on how French managers pay attention to the execution of orders as well as its immediacy, our results confirm the immediacy. As documented half of the French managers rarely ask for immediate execution, i.e. a transaction executed within 10 minutes [35]. They indicate that seven (7) investors out of ten (10) leave the discretion to fund managers a time limit of three hours to one day. Our results globally indicate that stock market orders are executed on average between three (3) and seven (7) days. As a result, investors who are impatient or in a hurry will find it hard to be rewarded on the Regional Stock Exchange and those with private information may not benefit because of the contagion of information. But it should be noted that stocks are more accessible than bonds. However, the ease with which they are accessible depends on the depth of the market, but also on the ability of investors to place stock market orders in a timely manner.

In addition, the results also reveal that the retention period for stocks and bonds is on average more than one year, both for individuals and for legal entities. This assumes that investors are in the logic of immobilizing securities on the Regional Stock Exchange. Thus, the stock market of the Regional Stock Exchange looks like a savings market where each investor buys and waits for dividends. When investors hold their shares for long periods of time and avoid speculating, the number of investors who can participate in the trading of securities in the market is reduced. As a result, companies that have a surplus of cash and wish to place on the market by buying securities will have difficulty in doing so in the regional market.

\subsection{Liquidity, Process Dimension Versus Static Dimension}

From what the results show, it seems important to consider whether the production of liquidity follows a process or is 
static. It may be accepted that liquidity is process governed if it is built gradually through a regulatory process driven by the market authorities. For example, the regulatory process, like microstructure changes, aims to promote natural liquidity in the stock markets. In the static sense, we can make a conclusion that, if a market reaches a so-called liquid phase, this liquidity remains in space and in duration. From this stand point, let us recall from our analysis model that liquidity is a game of behavior of the investors who play a role in the market. Along the same line, it is dependent on investor confidence according to [36]. As a result, it does not depend solely on regulation (liquidity contract), but is a shared belief of investors. It is highly dependent on sufficient investors in terms of numbers, interacting in the market, their expectations of future price developments, the risk incurred and the availability of information [13]. Thus, and with reference to Keynesian doctrine, particularly the preference of agents to hold an asset or currency, one can understand the analysis of liquidity. Keynes's analysis assumes a psychological behavior and a position of the economic agent who is in a situation where he must determine his preferences [16]. The analysis argument is of a behavioral nature but only refers to speculative behavior. However, human behavior is a function of the circumstances and the economic environment. It is therefore diversified according to the expectations of investors as underlined [37]. From this point of view, if we agree that liquidity is dependent on investor behavior and that the behavior itself is dynamic, we cannot conclude that liquidity is neither process governed nor static. From this point of view, is not stock market liquidity simply a utopia?

The discussions on investor behavior that we have just conducted deserve a profound questioning of the very concept of liquidity. Investors' retention of securities for a long period of time leads to under-liquidity in a market, but it is an investment strategy in itself. When the investor decides not to sell his securities in the short term, it is because they expect capital gains on dividends rather than price changes. It is not surprising to see investors who permanently or in life time immobilize securities, despite the impetus of continuous rating that offers permanent "back and forth" on the market. It should be remembered that the continuous listing has the advantage of allowing the investor to place stock market orders at any moment (instantaneity) with the possibility of limiting the risk of non-execution of his order [35]. Whatever the architecture or microstructure of a stock exchange, the production of natural liquidity is not possible without the willingness of investors to release their securities at any time. It turns out that this desire is sometimes linked to the investment horizon or each investor is free, without any pressure, to exchange or not. Under these conditions, the liquidity sought on the financial markets in general and in particular on stock exchanges will be a utopia.

\section{Conclusion}

The purpose of this article was to study the liquidity of the Regional Stock Exchange through investor behavior and float level. The analysis of the real facts shows that investors are passive on the Regional Stock Exchange. This behavior leads to a reduction in liquidity due to the reduction in the number of investors in the market. From this it can be deduced that the West African Stock Market is a savings market where investors are only waiting for dividends. The results reveal that the average time that a stock market order finds a counterparty is between three (3) to seven (7) days. This situation is due to the scarcity of securities and / or the inability of investors to operate in the market in a right time. This means that new entrants will find it difficult to afford securities for lack of abundant liquidity. However, it should be noted that equities are more accessible than bonds.

The results have a theoretical and methodological contribution. In terms of methodological contribution, it should be noted that the phenomenon of liquidity has been studied according to an approach that is not usual in behavioral finance. We combined in this research a quantitative study and a qualitative study according to the Likert scales technique. This methodological triangulation remains an important contribution to our sense. Also, it is accepted in the literature that the statistical analysis of the data makes it possible to isolate and study the behavior of individuals outside the experiment. However, we were able to set an approach that is different from experimentation. From this point of view, it is one of the first experiences that are proven to be a rich methodology in the field of behavioral finance. In terms of theoretical contributions, most of the work on market liquidity does not insist on our knowledge of individual behavior, let alone the scarcity of securities. However, there is an unanswered question. Is it not the behavior of investors on the stock market that leads to the scarcity of securities or vice versa? This question probably opens ways of empirical investigation research with testable vocation, another significant theoretical implication. Undoubtedly, this paper has many implications but it runs up against a limit. This is the sample size. Moreover, the model deserves to be tested. In this context, it is therefore appropriate for future research to expand the sample.

\section{References}

[1] Orléans, A. (2004). Efficience, finance comportementale et convention: une synthèse théorique. Les crises financières, Rapport de Conseil d'Analyse Economique, Vol. 50, pp. 241-270.

[2] Ding, X. S., Ni, Y., \& Zhong, L. (2016). Free float and market liquidity around the world. Journal of Empirical Finance, Vol. 38, pp. 236-257.

[3] Bayala, S. (2002). La bourse régionale des valeurs mobilière, l'introduction en bourse: Pourquoi et pourquoi pas? Les sociétés et les investisseurs (Thèse de Doctorat).

[4] Van der Bile, R. (1994). Environnement de réglementation sur les marchés émergents. Revue d'économie financière, No. 29, pp. 41-57.

[5] Demsetz, H. (1968). Why regulate utilities? The Journal of Law and Economics, Vol. 11, No., pp. 55-65. 
[6] Chordia, T., Roll, R., \& Subrahmanyam, A. (2001). Market liquidity and trading activity. The journal of finance, Vol. 56, No. 2, pp. 501-530.

[7] Hearn, B., Piesse, J., \& Strange, R. (2010). Market liquidity and stock size premia in emerging financial markets: The implications for foreign investment. International Business Review, 19 (5), 489-501.

[8] Shefrin, H. (2010). Behavioralizing finance. Foundations and Trends in Finance, 4, 1184 p.

[9] De Winne, R., \& D’Hondt, C. (2017). La finance comportementale: enjeux et perspectives. Regards économiques, 1 .

[10] Wuyts, G. (2007). Stock market liquidity: Determinants and implications. Review of Business and Economics, Vol. 52, No. 2, pp. 279-316.

[11] Cornell, B. (2000). The relationship between volume and price variability in futures markets. Journal of futures markets, Vol. 20, No. 1, pp. 5-18.

[12] Fournier-Emonet, C. (2004). L'identification de facteurs communs de la liquidité sur le marché parisien des actions. Paris Dauphine cahier de recherche.

[13] Bervas, A. (2006). La liquidité de marché et sa prise en compte dans la gestion des risques. Revue de la stabilité financière, Vol. 8, pp. 67-84.

[14] Rezaei, E., \& Tahernia, A. (2012). The relationship between the percentages of free float shares and liquidity of shares in the companies accepted in Tehran Stock Exchange. African Journal of Business Management, Vol. 7, No. 37, pp. 37903798.

[15] Gravelle, T. (1999). Liquidity of the government of Canada securities market: stylized facts and some market microstructure comparisons to the United States treasury market. Bank of Canada.

[16] Penglaou, C. (1964). Brèves remarques sur la notion de liquidité. Revue économique, Vol. 15, No. 3, pp. 455-467.

[17] O'Hara, M. (2004). Liquidity and financial market stability. Working paper. No 55 (National Bank of Belgium).

[18] Biais, B., Glosten, L., \& Spatt, C. (2005). Market microstructure: A survey of micro foundations, empirical results, and policy implications. Journal of Financial Markets, Vol. 8, No. 2, pp. 217-264.

[19] Orléan, A. (2004). La bourse est-elle au service de la production? Rapport Moral sur l'Argent dans le Monde 2003, 2004, pp. 51-58;

[20] Autume, A. (1992). Théorie des jeux et marché. Cahiers d'économie politique/Papers in Political Economy, pp. 155165 .

[21] Broihanne et al (2005). Le comportement des investisseurs individuel. Revue française de gestion, No. 157, pp. 145-168.

[22] Raposo, J. (2003). L'étude comparative des différentes stratégies de placement d'ordres à la bourse de Paris (No. halshs-00163241);
[23] Moinas, S. (2008). Le carnet d'ordres: une revue de littérature. Finance, Vol. 29, No. 1, pp. 81-147.

[24] Szpiro, D. (1992). Points de repère sur le marché des actions des entreprises françaises. Revue d'économie financière, Vol. 20, pp. 29-50.

[25] Petitjean, M., \& Waelput, J. (2008). Volume, listing changes and liquidity contract on Alternext. Revue bancaire et financière, Vol. 8, pp. 488-496.

[26] Le Saout, E. (1999). Un indice de liquidité multidimensionnel. Banque et Marchés, Vol. 41, pp. 33-40.

[27] Kyle, A. S. (1985). Continuous auctions and insider trading. Econometrica: Journal of the Econometric Society, pp. 13151335.

[28] Economides, N., \& Schwartz, R. A. (2001). Equity trading practices and market structure: Assessing asset managers' demand for immediacy. In The Electronic Call Auction: Market Mechanism and Trading (pp. 169-205). Springer, Boston, MA.

[29] Oriol, N. (2012). La fragmentation des flux d'ordres et la révision de la directive MIF: apports de l'économie industrielle. Revue d'économie industrielle, Vol. 139, pp. 4976.

[30] Broye, G., \& Schatt, A. (2003). Pourquoi certains actionnaires cèdent-ils plus d'actions que d'autres lors de l'introduction en bourse? (No. 1030802). Université de Bourgogne-CREGO EA7317 Centre de recherches en gestion des organisations.

[31] Serve, S. (2007). L'impact de l'admission à la cote sur les performances économiques des entreprises. Finance, Vol. 28, No. 2, pp. 79-120.

[32] Yin, R., (1994). Case study research: Design and methods (2nd ed.). Beverly Hills, CA: Sage Publishing, (Zainal, Z. (2007). Case study as a research method. Jurnal Kemanusiaan, $5(1))$.

[33] Collerette, P. (1997). L'étude de cas au service de la recherche. Recherche en soins infirmiers, Vol. 50, pp. 81-88.

[34] M'barek B. (2001). Relation entre les firmes et actionnaires institutionnels. Promotion de l'investissement relationnel, document de recherche.

[35] Demarchi, M., \& Thomas, S. (1997). Actions françaises: interactions entre la gestion de portefeuille et la négociation en bourse. Revue d'économie financière, pp. 107-121.

[36] Bourghelle, D., \& Hyme, P. (2010). Du mythe de l'efficience des marchés au krach. L'illusion de la liquidité boursière. Revue de la régulation. Capitalisme, institutions, pouvoirs, no. 8.

[37] Rubinstein, M. (2006). Le développement de la responsabilité sociale de l'entreprise. Une analyse en termes d'isomorphisme institutionnel. Revue d'économie industrielle, Vol. 113, pp. 83105. 